\title{
Relation of bleeding patterns and factor VIII levels in children with hemophilia
}

\author{
Rina Rahardiani, H. S. Moeslichan MZ, Agus Firmansyah
}

\begin{abstract}
Background The high costs of factor VIII examination cause the delay in the diagnosis of hemophilia $A$; consequently many patients do not receive adequate therapy which results in failure to survive into adulthood or survive with creeple.

Objective To determine bleeding patterns of hemophilia A patients for the prediction of its classification.

Methods We perform retrospective analysis of hemophilia patients at the Integrated Service Center of Hemophilia, Cipto Mangunkusumo Hospital, Jakarta.

Results Family history, age at the first bleeding, frequency of bleeding, and factor VIII examination can significantly differentiate the classification of hemophilia A $(P=0.015 ; 0.014 ;<0.0001$; and $<0.0001$, respectively) while age groups, triggering trauma for the first bleeding, type of the first bleeding, history of previous trauma, the most frequent type of bleeding, age at diagnosis, and consumption of cryoprecipitate cannot. $(P=0.985 ; 0.475 ; 0.342 ; 0.318$; 0.058; 0.477; and 0.547, respectively).

Conclusion Age at first bleeding, frequency of bleeding, and family history can be used to predict classification of hemophilia A. [Paediatr Indones 2006;46:159-163].
\end{abstract}

Keywords: hemophilia A, bleeding patterns, hemophilia classification.

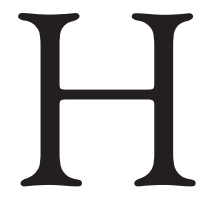
emophilia A is a hereditary blood coagulation disorder caused by deficiency of factor VIII. Based on the degree of clinical manifestations and laboratory examination, patients are classified into 3 groups, namely severe, moderate, and mild hemophilia A. Severe hemophilia $A$ is established if the activity of factor VIII is less than $1 \%$ characterized by bleeding that occurs spontaneously or preceded by previous mild trauma; the onset of bleeding is usually below one year of age and the patients often get bleeding problems. Moderate hemophilia is established if the activity of factor VIII ranges from 1 to $5 \%$; bleeding often occurs following moderate trauma and the patients seldom get bleeding problems. Mild hemophilia $A$ is established if the activity of factor VIII was ranged from 5-30\%; bleeding occurs following severe trauma or post-operatively; most of the patients are often underdiagnosed until they reach adulthood., ${ }^{1,2}$

It is predicted that there are approximately 450000 severe or moderate-severe hemophilia patients worldwide, with $75 \%$ of them are in developing countries and do not receive adequate therapies. ${ }^{3,4}$ The high cost of the laboratory test is one of the obstacles for early diagnosis of hemophilia A so that the patient do not receive adequate therapy which results in failure of survive into adulthood or survive with creeple. ${ }^{4}$ The disabilities are often permanent and require surgery. It may reduce productivity and rise

From the Department of Child Health, Medical School, University of Indonesia, Jakarta, Indonesia.

Reprint requests to: Rina Rahardiani, MD, Department of Child Health, Medical School, University of Indonesia, Cipto Mangunkusumo Hospital, Jl. Salemba 6, Jakarta, Indonesia. Tel. 62-21-3161144. Fax. 62-21-3907743. 
psychological problems. ${ }^{4}$ Disability can be prevented if patients with severe hemophilia can receive appropriate therapy at early age. Considering the large numbers of hemophilia and the limitation of factor VIII levels measurement, the classification of this disorder can not be determined. This study was conducted to elicit the bleeding patterns of hemophilia A patients so that the classification could be predicted.

\section{Methods}

This study was conducted at the Integrated Service Center for Hemophilia, Cipto Mangunkusumo Hospital, Jakarta, from August 2003 until March 2004.

The inclusion criteria were all hemophilia A patients who got bleeding episodes. Informed consent from the parents were obtained prior to the study. Data of the patients (history and factor VIII levels) were derived from the medical records. Data of anamnesis included patients' age, age at the first bleeding, age at diagnosis, history of previous trauma, frequency of bleeding within one year, type of the first bleeding, type of the most bleeding episodes, the most frequent bleeding episodes, family history, and consumption of cryoprecipitate each for bleeding episodes. The data obtained were then tabulated into the main table and processed by Excel and SPSS, version 10.07 for Windows.

\section{Results}

Collection of data from August 2003 to March 2004 yielded 113 patients. Based on the results of the laboratory examination, 6 patients were not proven as having hemophilia A and were excluded from the study. The number of patients who fulfilled the criteria was 107 patients consisted of 13 mild (12\%), 44 moderate (41\%), and 50 severe hemophilia A patients (47\%). Table 1 shows the relationship between the risk factors and hemophilia A classifications.

Table 1 shows that there was no significant difference among the 3 classifications of hemophilia A according to the patient's age, the triggering trauma for the first bleeding, the type of first bleeding, history of previous trauma, and the most frequent type of bleeding, whereas the family history was significantly
Table 1. Relationship betWeen Risk factors AND HEMOPHILIA A CLASSIFICATION ( $\mathrm{N}=107$ )

\begin{tabular}{|c|c|c|c|c|}
\hline \multirow{2}{*}{ Risk factors } & \multicolumn{3}{|c|}{ Classification hemophilia } & \multirow{2}{*}{$\mathbf{P}$} \\
\hline & Mild & Moderate & Severe & \\
\hline \multicolumn{5}{|l|}{ Age group } \\
\hline$<10$ years & 4 & 15 & 17 & 0.985 \\
\hline $10-19$ years & 7 & 19 & 22 & \\
\hline$>20$ years & 2 & 10 & 11 & \\
\hline \multicolumn{5}{|l|}{$\begin{array}{l}\text { Trauma triggering } \\
\text { the first bleeding }\end{array}$} \\
\hline Yes & 7 & 19 & 18 & 0.475 \\
\hline No & 6 & 25 & 32 & \\
\hline \multicolumn{5}{|c|}{ Type of first bleeding } \\
\hline Skin & 10 & 34 & 40 & 0.342 \\
\hline Mucosal membran & & & & \\
\hline (mouth, nose, eye) & 0 & 6 & 4 & \\
\hline Joint and muscle & 1 & 2 & 2 & \\
\hline Others & 2 & 2 & 4 & \\
\hline \multicolumn{5}{|c|}{$\begin{array}{l}\text { History of previous trauma } \\
\text { (especially joint bleeding) }\end{array}$} \\
\hline No & 2 & 3 & 0 & 0.318 \\
\hline Spontaneous & 1 & 11 & 29 & \\
\hline Mild trauma & 4 & 23 & 20 & \\
\hline Moderate trauma & 6 & 7 & 1 & \\
\hline \multicolumn{5}{|l|}{$\begin{array}{l}\text { Type of the most } \\
\text { frequent bleeding }\end{array}$} \\
\hline Mouth & 0 & 0 & 1 & 0.058 \\
\hline Muscle & 4 & 4 & 3 & \\
\hline Joint & 9 & 40 & 46 & \\
\hline \multicolumn{5}{|l|}{ Familial history } \\
\hline Yes & 10 & 29 & 32 & 0.015 \\
\hline No & 3 & 15 & 18 & \\
\hline
\end{tabular}

related with the classification of hemophilia A. Table 1 also shows that skin bleeding was the most frequent type of first bleeding. Other types of bleeding included post-immunization bleeding, post-circumcision bleeding, and post-operative bleeding. Bleeding following immunization was experienced by two severe hemophilia patients and by one moderate hemophilia patients. The bleeding occurred at 3 months of age (the first immunization).

In Table 2, age at the first bleeding, frequency of bleeding, and factor VIII examination could significantly differentiate the three classification of hemophilia A ( $\mathrm{P}=0.041 ; 0.000$; and 0.000 , respectively), whereas patient's age, age at diagnosis, and consumption of cryoprecipitate significantly could not.

\section{Discussion}

Most of hemophilia A patients in this study were between 10-19 years old (45\%) and approximately $34 \%$ of them were below 10 years old. Age of patients 
Rina Rahardiani et al: Relation of bleeding patterns and factor VIII levels in hemophilia

Table 2. Mean Variable values according to classification of hemophilia $A$

\begin{tabular}{|c|c|c|c|c|c|c|c|}
\hline \multirow{2}{*}{ Variables } & \multicolumn{2}{|c|}{ Mild $(n=13)$} & \multicolumn{2}{|c|}{ Moderate $(n=44)$} & \multicolumn{2}{|c|}{ Severe $(n=50)$} & \multirow[b]{2}{*}{$\mathbf{P}$} \\
\hline & Mean & SD & Mean & SD & Mean & SD & \\
\hline Age $(y r)$ & 13.5 & 8.0 & 14.3 & 7.5 & 13.6 & 6.6 & 0.843 \\
\hline Age at diagnosis (month) & 48.3 & 55.8 & 25.1 & 31.2 & 24.4 & 20.5 & 0.477 \\
\hline Age at first bleeding (month) & 31.9 & 46.5 & 10.6 & 18.5 & 6.0 & 3.9 & 0.041 \\
\hline Bleeding frequency (/year) & 6.5 & 6.8 & 16.5 & 10.8 & 41.2 & 13.7 & $<0.0001$ \\
\hline Factor VIII level (UI/dl) & 17.9 & 11.8 & 2.7 & 1.4 & 0.5 & 0.0 & $<0.0001$ \\
\hline Cryoprecipitate consumption (U/kg) & 16.1 & 4.2 & 16.9 & 3.8 & 17.3 & 3.7 & 0.547 \\
\hline
\end{tabular}

could not be used to predict the classification of hemophilia A, because the classification of hemophilia is based on factor VIII levels. ${ }^{1,2}$

Based on the classification of hemophilia A, most of the patients belonged to severe hemophilia (47\%), which was in accordance with the literature. ${ }^{3}$ The study conducted by Ljung et a ${ }^{5}$ revealed that $52 \%$ of them were severe hemophilia and only $29 \%$ were mild hemophilia. ${ }^{5}$ In the study conducted by Nilsson et al, ${ }^{6}$ it was found that the number of mild hemophilia A patients was $54 \%$, while severe hemophilia A patients was only $30 \%$. Based on the epidemiological study, mild hemophilia A patients proportionally should have been found in out of $50-55 \%$ of the total population. The small number of mild hemophilia A patients could be attributed to the underdiagnosis of the disease. ${ }^{5}$

In this study, most of the first bleeding episodes were cutaneous bleeding that often occurred spontaneously. The second most frequent bleeding was mucosal bleeding followed with joint bleeding, and others, muscles, navel. Mucosal bleeding, joints, and other bleeding were preceded by the history of trauma. It is in accordance with that stated in the literature, that clinical manifestations of the first bleeding experienced by the patients included cutaneous bleeding; this bleeding can occur spontaneously or as a result of trauma. This kind of bleeding can also occur in all areas of the body but most of them is confined to the legs and arms due to excess activity that is often suspected as child-abuse.

The study conducted by Ljung et al in 1990 found that the first bleeding episode experienced by the patients was subcutaneous bleeding (41\%); bleeding related with injections or surgery (16\%), and oral mucosal bleeding (11\%). The second type of bleeding after cutaneous bleeding was oral mucosal bleeding. ${ }^{1,2}$ Bleeding occurred during the eruption of permanent teeth or due to trauma to the oral mucosa.
Joint bleeding in this study was experienced by 2 severe and moderate hemophilia $A$ patients aged 10 and 12 months respectively by the time they were learning to walk. This finding is in line with that stated in the literature..$^{1,6,8}$

Trauma triggering the first bleeding could not be used to predict the classification of hemophilia due to the fact that most of bleeding episodes occurred spontaneously. The history of previous trauma could not be used either to predict classification of hemophilia A. According to the literature, severe hemophilia have spontaneous bleeding or due to the previous trauma, whereas moderate hemophilia have bleeding following the history of moderate trauma and mild hemophilia experience bleeding following severe trauma or after surgical procedure. ${ }^{1,2,8}$ In this study, most of the subjects had spontaneous bleeding or due to the previous trauma. It could be atttributed to the inadequate therapy; doses were given not in accordance with the prescription, or due to the delay in therapy initiation, or drug withdrawal before the bleeding stopped. If treated adequately, joint bleeding will recover totally; if the therapy is late or inadequate, the patients are prone to recurrent bleeding on the same organ. Recurrent bleeding can happen spontaneously and can impose damage of the affected joint. ${ }^{6,9,10}$ It is of paramount importance to realize that once the bleeding happens even in mild hemophilia, proper management should be given. ${ }^{11}$

The most frequent type of bleeding experienced by the patients was joint bleeding (89\%). It was stated in the literature that the most typical bleeding symptoms for hemophilia is joint bleeding followed with muscular bleeding. This kind of bleeding can occur 30-35 times/year in severe hemophilia. ${ }^{12}$ Type of bleeding cannot be used to predict classification of hemophilia due to the fact that $89 \%$ of them had joint bleeding. 
Up to 71 subjects $(66 \%)$ were found to have family history of hemophilia. This is in line with the literature that $30 \%$ of patients have no family history of hemophilia due to high occurrence of spontaneous mutation. ${ }^{1}$ Familial history can be used to predict classification of hemophilia. If someone suffers from hemophilia and has a relative who suffers from the disease with the same clinical symptoms, the relative is more likely to have the same disease with factor VIII level in the same variation as in that family. 13

Age at diagnosis could not be used to predict classification of hemophilia because most of the subjects were late diagnosed. The delay was caused by the lack of provision of the reagent for factor VIII examination and by the relatively high cost for the assessment. ${ }^{6}$

In this study, age at the first bleeding could be used to predict the three type classifications of hemophilia A. The first bleeding was experienced by severe hemophilia patients at the approximate age of six months, moderate hemophilia at 10.8 months, whereas mild hemophilia at the mean age of 31.9 months. ${ }^{6,7}$ In the study conducted in Sweden, severe hemophilia got the first bleeding episodes after they reached 9 months of age and moderate hemophilia at 22 months of age. ${ }^{6}$ Mild hemophilia usually get the first bleeding following severe trauma or post-operatively and most patients are underdiagnosed until they reach adulthood. ${ }^{6,13}$ In this study, factor VIII levels for moderate hemophilia were $2.7 \%$ which were quite close to the level for moderate-severe hemophilia (2\%) so the clinical symptoms were almost similar with those of severe hemophilia. Mild hemophilia got the first bleeding following trauma such as after circumcision and skin bleeding due to blunt trauma.

In our series annual bleeding frequency could be used to predict the three type classifications of hemophilia. Severe hemophilia was afflicted by 41 bleeding episodes annually whereas moderate hemophilia got 16 bleeding episodes and mild hemophilia got 6 bleeding episodes. Previous studies reported that severe hemophilia could have 35 bleeding episodes yearly, moderate hemophilia could get 12 bleeding episodes yearly, and mild hemophilia could get none. ${ }^{1,9}$ In this study, bleeding frequency of subjects was higher which could be attributed to the lack of education for the patients and their families so that they were not aware about the importance of adequate therapy with the consequence of more frequent bleeding. Other literature stated that by knowing the basal level of factor VIII, probability of bleeding frequency experienced by severe hemophilia could be predicted. Based on this knowledge, the patients are usually recommended to receive prophylactic therapy at early age after they have the first bleeding episodes. ${ }^{1}$

The level of cryoprecipitate could not be used to predict classification of hemophilia due to the fact that the doses administered to most of the subjects were lower than prescribed doses. In the literature, the doses given in developed countries can be precisely calculated because factor VIII concentrate has been used for a long time; the recommended minimal dose is $25 / \mathrm{U} / \mathrm{kg} .1,2,6$

In conclusion, the age at the first bleeding, bleeding frequency, and family history of hemophilia can be used to predict the classification of haemofilia A.

\section{References}

1. Montgomery RR, Scot JP. Hemostasis: Disease of the fluid phase. In: Nathan DG, Oski FA, editors. Hematology of infancy and childhood. 4th ed. Philadelphia: Saunders; 1993. p. 1605-50.

2. Corrigan JJ. Hemorrhagic disorder. In: Berhman RE, Kleigman RM, Nelson WE, Vaughan III VC, editors. Nelson textbook of pediatrics. 15th ed. Philadelphia: Saunders; 1996. p. 1424-7.

3. Srivastava A. Delivery of hemophilia care in the developing world. Hemophilia 1998;4:33-40.

4. Isarangkura P. Hemophilia care in the developing world: Benchmarking for excellence. Hemophilia 2002;8:205-10.

5. Ljung R, Vournas AS, Auberger KK. Treatment of children with hemophilia in Europe: A survey of 20 centres in 16 countries. Hemophilia 2000;6:619-24.

6. Nillson IM. Hemophilia. Malmo: Pharmacia plasma product;1994. p. 2-98.

7. Carvell JE, Duthie RB. Management of the hemophilic knee. In: Insall JN, editor. Surgery of the knee. 1st ed. New York: Churchill Livingstone;1998. p. 741-74.

8. Lusher JM, Warrier I. Hemophilia A. Hematol Oncol Clin North Am 1992;6:1021-33. 
9. Dimichele D, Neufeld EJ. Hemophilia: A new approach to an old disease. Hematol Oncol Clin North Am 1998;12:1315-44.

10. On Wuzurike N, Warrier I, Lusher M. Types of bleeding seen during the first 30 month of life with severe hemophilia A and B. Hemophilia 1996;2:13740.

11. Jones P. Guideline for the development of national programme for hemophilia. Newcastle: World Federa- tions of hemophilia; 1996. p. 1-48.

12. Corrigan JJ. Coagulation disorders. In: Miller DR, Baechner RL, editors. Blood disease of infancy and childhood. 6th ed. Saint Louis: CV Mosby Company; 1990. p. 47-65.

13. Hillgartner MW, Mc Milan CW. Coagulation disorder. In: Miller DR, Pearson HA, Bachner RL, editors. Smith's blood diseases of infancy and childhood. 4th ed. Saint Louis; 1978. p. 771-90. 